\title{
Kinetic Analysis of Fast Mass Transfer across Oil/Water Interface Using Single Microdroplet Injection and Potential Step Electrolysis
}

\author{
Kiyoharu NaKaTANI and Takayuki NegiSHI \\ Department of Chemistry, University of Tsukuba, Tsukuba 305-8571, Japan
}

(Received April 25, 2001; Accepted June 14, 2001)

\begin{abstract}
A study of the mass transfer (MT) across an oil/water interface is important for the fundamental understanding of liquid/liquid extraction, biological membranes, and so on. The kinetic analysis of the fast MT of neutral species across an oil/water interface is difficult since the MT occurs during the construction of the oil/water interface. Several efforts have been devoted to the direct kinetic analyses of the fast MT of neutral species. ${ }^{1-6}$ In mm-sized oil/water interface systems, however, the analysis of the overall extraction rate including a fast interfacial process is frequently complicated by nonsteady-state linear diffusion from the bulk solution phase to the interface. In $\mu \mathrm{m}$-sized droplet/solution interface systems, on the other hand, the MT from the bulk solution phase to the microdroplet surface is steady-state spherical diffusion and is relatively fast.? Therefore, the kinetic analysis of the fast interfacial MT can occur in single-microdroplet/solution systems. In this study, we propose single microdroplet injection and potential step electrolysis of the droplet to initiate the MT from the solution to the droplet. We applied the technique to the fast interfacial MT. Electrochemical measurements were performed without supporting electrolytes to demonstrate the interfacial MT as a model of actual liquid/liquid extraction systems.
\end{abstract}

\section{Experimental}

A single tributyl phosphate (TBP) droplet was injected $\left(10^{-11}\right.$ $\mathrm{dm}^{3}$ ) into an aqueous (ferrocenylmethyl) trimethylammonium bromide $\left(\mathrm{FcN}^{+} \mathrm{Br}^{-} ; \mathrm{FcN}^{+}\right.$concentration in water $\left(\left[\mathrm{FcN}^{+}(\mathrm{w})\right]\right)=$ $\left.0.5 \mathrm{mM}, 1 \mathrm{M}=1 \mathrm{~mol} / \mathrm{dm}^{3}\right)$ and $\mathrm{NaPF}_{6}\left(\mathrm{PF}_{6}{ }^{-}\right.$concentration in water $\left(\left[\mathrm{PF}_{6}-(\mathrm{w})\right]\right)=0.5$ or $\left.1 \mathrm{mM}\right)$ solution $\left(7 \mathrm{~cm}^{3}\right)$ and put into contact with a gold disk microelectrode $(25 \mu \mathrm{m}$ in diameter $)$, fabricated in a glass capillary $(\sim 70 \mu \mathrm{m}$ in diameter $)$, using an injection-manipulation system (Narishige Co., Ltd., MN-151, MMW-200/IM-16) under an optical microscope (Nikon Co., Ltd., SMZ-U). As the counter and reference electrodes, Pt wire and $\mathrm{Ag} / \mathrm{AgCl} / \mathrm{NaCl}$ (sat.) electrodes were used. The electrochemical responses of the single droplet were measured by an electrochemical analyzer (BAS Inc., BAS100B/W). All measurements were performed at room temperature $\left(20-22^{\circ} \mathrm{C}\right)$.

\section{Results and Discussion}

A single TBP droplet was injected and covered on the microelectrode surface. The contact angle between the glass insulator and TBP in water was $\sim 90^{\circ}$. A cyclic voltammogram
(CV) of a single TBP droplet with $d_{\mathrm{x}}=20 \mu \mathrm{m}$ and $d_{\mathrm{y}}=33 \mu \mathrm{m}$ is shown in Fig. 1, where $d_{\mathrm{x}}$ and $d_{\mathrm{y}}$ are the distance from the electrode to the droplet surface normal to the electrode surface and the droplet diameter parallel to the electrode surface, respectively. A current $(i)$-potential $(E)$ curve corresponding to the oxidation of $\mathrm{FcN}^{+}$to $\mathrm{FcN}^{2+}$ was sigmoidal, analogous to that observed in a homogeneous solution using a microelectrode. ${ }^{7}$ No electrochemical response of $\mathrm{FcN}^{+}$without $\mathrm{PF}_{6}{ }^{-}$was detected. A cathodic current for the reduction of $\mathrm{FcN}^{2+}$ was not observed, since the dication would rapidly distribute into the water. When a neutral ferrocene derivative was extracted into a single droplet, the CV was a symmetrical peaked curve, as previously reported. ${ }^{8,9}$ Since extraction of the solute from the water to the droplet was slow $(>\sim 10 \mathrm{~s})$, the solute was completely electrolyzed during the forward potential sweep in the previous systems. These results indicate that the ion pair extraction of $\mathrm{FcN}^{+}$with $\mathrm{PF}_{6}{ }^{-}$is fast in the present system $(<\sim 10 \mathrm{~s})$.

In previous reports, the extraction rate was analyzed as the time dependence of the $\mathrm{CV}(>\sim 10 \mathrm{~s})$ due to the slow extraction rate. ${ }^{8,9}$ However, the ion pair extraction of $\mathrm{FcN}^{+}$and $\mathrm{PF}_{6}{ }^{-}$is so fast that it is difficult to quantitatively analyze the extraction process on the basis of the CV measurements. To determine the fast interfacial MT rate, triple potential step electrolysis was applied to the single droplet/electrode system for the first time. A potential waveform versus time $(t)$ curve and the $i$ - $t$ curve are shown in Fig. 2. The initial $E$ was $0.45 \mathrm{~V}$ and $E$ changed to 0.65 $\mathrm{V}(\Delta t=15 \mathrm{~s})$. At $0.65 \mathrm{~V}, i$ rapidly decreased to a steady-state

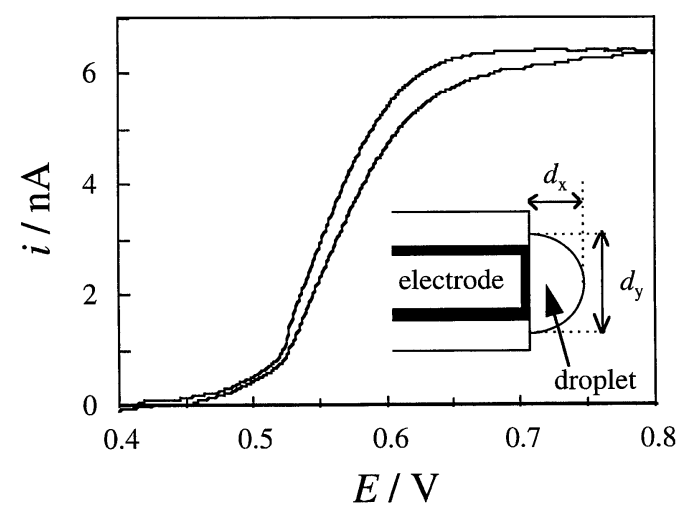

Fig. 1 Cyclic voltammogram of $\mathrm{FcN}^{+}$(potential sweep rate $=5$ $\mathrm{mV} / \mathrm{s})$ extracted into a single droplet $\left(d_{\mathrm{x}}=20 \mu \mathrm{m}, d_{\mathrm{y}}=33 \mu \mathrm{m}\right)$ at $\left[\mathrm{PF}_{6}^{-}(\mathrm{w})\right]=1 \mathrm{mM}$. 


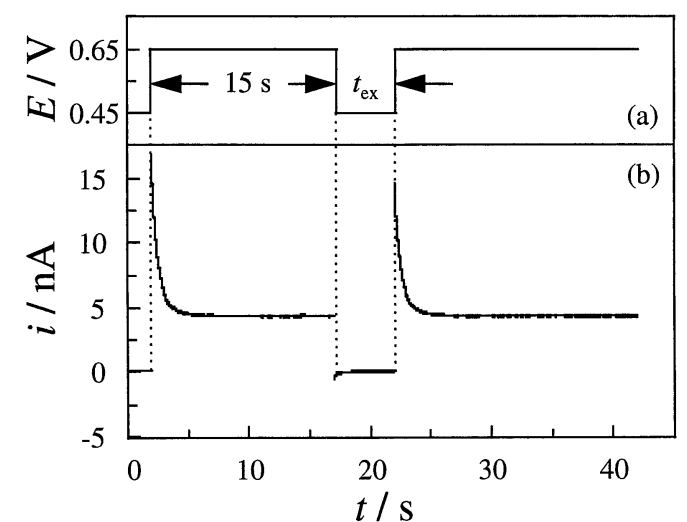

Fig. 2 Potential waveform (a) and the current response (b) for a single droplet $\left(d_{\mathrm{x}}=18 \mu \mathrm{m}, d_{\mathrm{y}}=30 \mu \mathrm{m}\right)$ at $\left[\mathrm{PF}_{6}^{-}(\mathrm{w})\right]=1 \mathrm{mM}$.

current $\left(i_{\mathrm{s}}\right)$, indicating that $\mathrm{FcN}^{+}$in the droplet is almost oxidized except for the solute entering the droplet during the steady-state. In the present system, the migration of solutes in the droplet and the potential drop will not be neglected, due to the absence of supporting electrolytes when the current flows through the system. Therefore, the $i-t$ curve was not directly analyzed. After the electrolysis of $\mathrm{FcN}^{+}, E$ was stepped to 0.45 $\mathrm{V}\left(\Delta t=t_{\mathrm{ex}}, t_{\mathrm{ex}}\right.$; extraction time), at which $\mathrm{FcN}^{+}$is extracted into the droplet. $E$ was then changed again to $0.65 \mathrm{~V}$ and the $i-t$ curve was measured for calculation of the $\mathrm{FcN}^{+}$molecules in the droplet as the total electric charge $\left(Q=\int\left(i-i_{\mathrm{s}}\right) \mathrm{d} t\right)$. Since a charging current due to the potential step from $0.65 \mathrm{~V}$ to $0.45 \mathrm{~V}$ is negligibly small, that from $0.45 \mathrm{~V}$ to $0.65 \mathrm{~V}$ will be small compared with the Faradaic current.

Analogous measurements were performed at various $t_{\mathrm{ex}}$ values for the same droplet and the $t_{\mathrm{ex}}$ dependence of $Q$ was then plotted (Fig. 3). The $Q$ value increased with $t_{\text {ex }}$ and the time required for the saturation of $Q$ increased with increasing $\left[\mathrm{PF}_{6}-(\mathrm{w})\right]$. A total $\mathrm{FcN}^{+}$concentration in the droplet at the extraction equilibrium $\left(\left[\mathrm{FcN}^{+} \mathrm{PF}_{6}-(\mathrm{o})\right]\right)$ can be determined from the saturated $Q$ value. Decreases in the $\mathrm{FcN}^{+}$and $\mathrm{PF}_{6}^{-}$ concentrations at the extraction equilibrium are negligibly small due to the small droplet volume $\left(10^{-11} \mathrm{dm}^{3}\right)$, therefore, the extraction constant, $K_{\mathrm{ex}}=\left[\mathrm{FcN}^{+} \mathrm{PF}_{6}^{-}(\mathrm{o})\right] /\left[\mathrm{FcN}^{+}(\mathrm{w})\right]\left[\mathrm{PF}_{6}^{-}(\mathrm{w})\right]$, is calculated to be $1.4 \times 10^{4} \mathrm{M}^{-1}$. This value is in good agreement with that determined by an ordinary extraction experiment $\left(K_{\mathrm{ex}}\right.$ $\left.=1.6 \times 10^{4} \mathrm{M}^{-1}\right)$ from water $\left(9 \mathrm{~cm}^{3} ;\left[\mathrm{FcN}^{+}(\mathrm{w})\right]=0.5 \mathrm{mM}\right.$, $\left.\left[\mathrm{PF}_{6}-(\mathrm{w})\right]=1 \mathrm{mM}\right)$ to $\mathrm{TBP}\left(2 \mathrm{~cm}^{3}\right)$.

The overall extraction rate is fast in the present system. The extraction rate is therefore expected to be governed both by the diffusion of the solutes in the bulk phases and by the MT at the droplet/water interface. To separate the diffusion and interfacial MT processes, the $Q-t_{\text {ex }}$ curve was analyzed on the basis of digital simulations of a hemispherical droplet. We assume that ion pair formation between $\mathrm{FcN}^{+}$and $\mathrm{PF}_{6}{ }^{-}$does not proceed in the water phase, and that the ion pair and/or the dissociated ions exist in the droplet. The $t_{\mathrm{ex}}$ dependence of a radial concentration profile $\left(C\left(r, t_{\mathrm{ex}}\right)\right)$ of a solute in the water phase or the droplet is given by Eq. (1).

$$
\partial C\left(r, t_{\mathrm{ex}}\right) / \partial t_{\mathrm{ex}}=D\left[\partial^{2} C\left(r, t_{\mathrm{ex}}\right) / \partial r^{2}+(2 / r) \partial C\left(r, t_{\mathrm{ex}}\right) / \partial r\right]
$$

where $r$ is the radially directed spatial coordinate and $D$ is the diffusion coefficient of the solute. In this simulation, the $D$ value of $\mathrm{PF}_{6}^{-}$in the water or the solutes in the droplet was used as the same values as that of $\mathrm{FcN}^{+}$in water $\left(6 \times 10^{-6} \mathrm{~cm}^{2} / \mathrm{s}\right)$ or

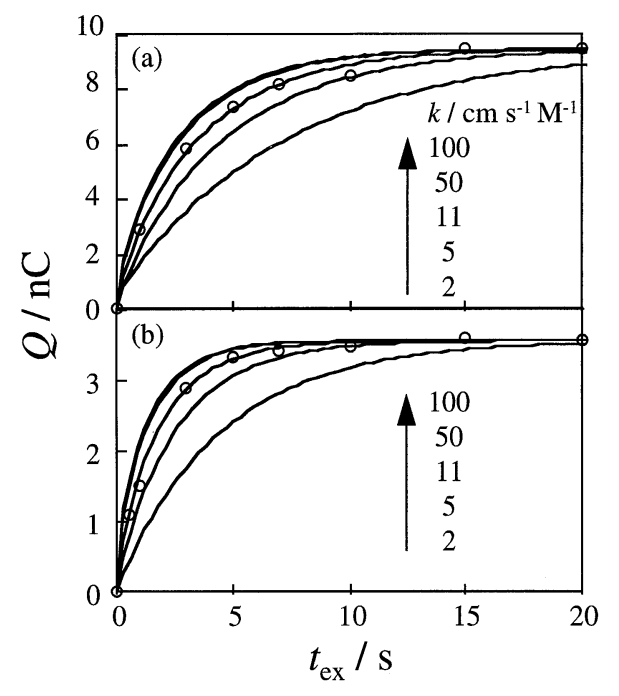

Fig. 3 Extraction time dependencies of $Q$ for single droplets at $\left[\mathrm{PF}_{6}-(\mathrm{w})\right]=1 \mathrm{mM}\left(d_{\mathrm{x}}=20 \mu \mathrm{m}, d_{\mathrm{y}}=33 \mu \mathrm{m}\right)(\mathrm{a})$ and $\left[\mathrm{PF}_{6}-(\mathrm{w})\right]=0.5$ $\mathrm{mM}\left(d_{\mathrm{x}}=21 \mu \mathrm{m}, d_{\mathrm{y}}=31 \mu \mathrm{m}\right)(\mathrm{b})$. The solid lines represent the simulation of $Q$.

TBP $\left(2 \times 10^{-6} \mathrm{~cm}^{2} / \mathrm{s}\right)$ (determined by separate CV experiments in solution), respectively. The interfacial MT rates from the water to the droplet and from the droplet to the water are assumed to be $k(A / V)\left[\mathrm{FcN}^{+}(\mathrm{w})\right]_{\text {int }}\left[\mathrm{PF}_{6}^{-}(\mathrm{w})\right]_{\text {int }}$ and $k(A / V)\left[\mathrm{FcN}^{+} \mathrm{PF}_{6}^{-}(\mathrm{o})\right]_{\text {int }} / K_{\text {ex }}$, where $k$ is the water-to-droplet MT rate constant per unit interfacial area of the droplet and $\left[\mathrm{FcN}^{+}(\mathrm{w})\right]_{\text {int }}, \quad\left[\mathrm{PF}_{6}^{-}(\mathrm{w})\right]_{\text {int }}$ and $\left[\mathrm{FcN}^{+} \mathrm{PF}_{6}^{-}(\mathrm{o})\right]_{\text {int }}$ are the concentrations of $\mathrm{FcN}^{+}, \mathrm{PF}_{6}^{-}$(in water), and the total $\mathrm{FcN}^{+}$(in droplet) near the interface, respectively. $A$ and $V$ are the interfacial area and the volume of the droplet, respectively. In actual simulations, $C\left(r, t_{\mathrm{ex}}\right)$ was simulated by a finite form for various $k$ values under the conditions of $\Delta t_{\mathrm{ex}}=0.2 \mathrm{~ms}$ and $\Delta r=$ $0.5 \mu \mathrm{m}$, and the $t_{\mathrm{ex}}$ dependence of $Q$ was calculated (Fig. 3). The overall extraction rate increased with increasing $k$. The calculated $Q$ values fall almost on the same curve at $k>\sim 50 \mathrm{~cm}$ $\mathrm{s}^{-1} \mathrm{M}^{-1}$, indicating that the rate-determining step of the extraction processes is the diffusion of the solutes in the bulk phases. The simulated curve at $k=\sim 10 \mathrm{~cm} \mathrm{~s}^{-1} \mathrm{M}^{-1}$ is in good agreement with the observed $Q$. It is noteworthy that the $k$ value is independent of $\left[\mathrm{PF}_{6}-(\mathrm{w})\right]$. The interfacial MT rate from the water to TBP at $\left[\mathrm{PF}_{6}-(\mathrm{w})\right]=0.5 \mathrm{mM}$ is estimated to be $5 \times$ $10^{-3} \mathrm{~cm} / \mathrm{s}$. Ions of a simple salt completely dissociated in a nitrobenzene/water system have been reported to transfer individually from water to nitrobenzene, maintaining the electroneutrality of the two phases. ${ }^{10}$ The ion extraction rate estimated from the kinetic and thermodynamic parameters of the each ion in the nitrobenzene/water system $\left(10^{-1}-10^{-2} \mathrm{~cm} / \mathrm{s}\right)$ was much larger than that in the present system. ${ }^{11}$ On the other hand, since an ion pair would not be dissociated in an oil phase with low dielectric constant $(<10)$, the ion pair extraction has been reported to depend highly on the ion association in the oil and water phases. ${ }^{12}$ The dielectric constant of TBP (8) is much smaller than that of nitrobenzene $(36),{ }^{13}$ so the ion association between $\mathrm{FcN}^{+}$and $\mathrm{PF}_{6}{ }^{-}$in $\mathrm{TBP}$ and/or at the droplet/water interface would be significantly related to the interfacial MT rate in the present system.

Using single microdroplet injection and the potential step electrolysis, the relatively fast ion pair extraction of the ferrocene derivative known as a typical redox species could be successfully analyzed without supporting electrolytes. Since $Q$ 
is independent of the electrode reaction rate, interfacial MT measurements of a solute in a single oil-droplet/water system can be performed for irreversible electrode reaction systems also. Therefore, the present technique will be sufficient to kinetically analyze the microscopic mechanisms of actual ion pair extraction systems using tris(1,10-phenanthroline)iron(II), Methylene Blue, and so forth.

\section{References}

1. H. Watarai, L. Cunningham, and H. Freiser, Anal. Chem., 1982, 54, 2390.

2. H. Nagatani and H. Watarai, Anal. Chem., 1998, 70, 2860.

3. J. Van Hunsel, G. Bleys, and P. Joos, J. Colloid Interface Sci., 1986, 114, 432

4. S. Shioya, S. Nishizawa, and N. Teramae, Langmuir, 1998, $14,4552$.

5. H. Yamada, S. Akiyama, T. Inoue, T. Koike, T. Matsue, and I. Uchida, Chem. Lett., 1998, 147.

6. A. L. Barker, J. V. Macpherson, C. J. Slevin, and P. R Unwin, J. Phys. Chem. B, 1998, 102, 1586.

7. A. J. Bard and L. R. Faulkner, "Electrochemical Methods: Fundamentals and Applications", 2000, John Wiley and Sons, New York, 156.

8. K. Nakatani, T. Uchida, N. Kitamura, and H. Masuhara, $J$. Electroanal. Chem., 1994, 375, 383.

9. K. Nakatani, M. Wakabayashi, K. Chikama, and N Kitamura, J. Phys. Chem., 1996, 100, 6749.

10. Y. Yoshida, M. Matsui, O. Shirai, K. Maeda, and S. Kihara, Anal. Chim. Acta, 1998, 373, 213.

11. J. Koryta and M. Skalicky, J. Colloid Interface Sci., 1988 , $124,44$.

12. S. Motomizu, Bunseki Kagaku, 1999, 48, 151.

13. J. A. Riddick and W. B. Bunger, "Techniques of Chemistry: Organic Solvent”, 1970, Vol. II, Wiley-Interscience, New York. 